\title{
Embryonal subregion-derived stromal cell lines from novel temperature-sensitive SV40 T antigen transgenic mice support hematopoiesis
}

\author{
Robert A. J. Oostendorp ${ }^{1, *}$, Alexander J. Medvinsky, ${ }^{2, *}$, Nuray Kusadasi ${ }^{3}$, Naoki Nakayama ${ }^{4}$, Kirsty Harvey ${ }^{1}$, \\ Claudia Orelio ${ }^{1}$, Katrin Ottersbach ${ }^{1}$, Todd Covey ${ }^{4}$, Rob E. Ploemacher ${ }^{3}$, Chris Saris ${ }^{4}$ and Elaine Dzierzak ${ }^{1, \neq}$ \\ ${ }^{1}$ Department of Cell Biology and Genetics, Erasmus University, Rotterdam, Netherlands \\ ${ }^{2}$ Centre for Genome Research, University of Edinburgh, Edinburgh, UK \\ ${ }^{3}$ Department of Hematology, Erasmus University, Rotterdam, Netherlands \\ ${ }^{4}$ Amgen, Thousand Oaks, CA, USA \\ *These authors contributed equally to this work \\ ¥Author for correspondence (e-mail: dzierzak@ch1.fgg.eur.nl) \\ Accepted 12 March 2002 \\ Journal of Cell Science 115, 2099-2108 (2002) (C) The Company of Biologists Ltd
}

\section{Summary}

Throughout life, the hematopoietic system requires a supportive microenvironment that allows for the maintenance and differentiation of hematopoietic stem cells (HSC). To understand the cellular interactions and molecules that provide these functions, investigators have previously established stromal cell lines from the late gestational stage and adult murine hematopoietic microenvironments. However, the stromal cell microenvironment that supports the emergence, expansion and maintenance of HSCs during mid-gestational stages has been largely unexplored. Since several tissues within the mouse embryo are known to harbor HSCs (i.e. aortagonads-mesonephros, yolk sac, liver), we generated numerous stromal cell clones from these mid-gestational sites. Owing to the limited cell numbers, isolations were performed with tissues from transgenic embryos containing the ts SV40 Tag gene (tsA58) under the transcriptional control of constitutive and ubiquitously expressing promoters. We report here that the growth and cloning efficiency of embryonic cells (with the exception of the aorta) is increased in the presence of the $t s A 58$ transgene. Furthermore, our results show that the large panel of stromal clones isolated from the different embryonal subregions exhibit heterogeneity in their ability to promote murine and human hematopoietic differentiation. Despite our findings of heterogeneity in hematopoietic growth factor gene expression profiles, high-level expression of some factors may influence hematopoietic differentiation. Interestingly, a few of these stromal clones express a recently described chordin-like protein, which is an inhibitor of bone morphogenic proteins and is preferentially expressed in cells of the mesenchymal lineage.

Key words: Stroma, Hematopoiesis, AGM, Development, $t s A 58$ transgene

\section{Introduction}

The microenvironment of the hematopoietic system is composed of stromal cells (Lord et al., 1975; Ogawa, 1993) that interact and regulate the hierarchy of hematopoietic stem cells (HSCs), progenitors, committed cells and functional circulating blood cells (Lemischka, 1991; Metcalf, 1988). Stromal cells within the context of the bone marrow (BM) and liver are thought to maintain and support hematopoiesis throughout adult and fetal stages, respectively (Jordan and Lemischka, 1990; Moore and Metcalf, 1970). Indeed, many BM and fetal liver stromal cell lines (Baum et al., 1992; Breems et al., 1994; Collins and Dorshkind, 1987; Deryugina et al., 1994; Lemoine et al., 1990; Moore et al., 1997a; Wineman et al., 1996) have served as the basis of culture systems for analyzing the growth, maintenance and differentiation of hematopoietic cells and have been demonstrated to be potent supporters of hematopoietic stem and progenitor cells. Such cells elaborate a variety of hematopoietic growth factors and have been used for subtractive cDNA cloning approaches (Moore et al., 1997b; Ohneda et al., 2000) to identify novel genes important in stromal cell function. More recently, developmental studies suggest that during early to midgestation, unique pre-fetal liver microenvironments in the yolk sac and the aorta-gonadsmesonephros (AGM) region also play an important role in the differentiation, generation, maintenance and perhaps even the expansion of the first hematopoietic cells in the mouse embryo (Dzierzak et al., 1998; Godin et al., 1999; Medvinsky and Dzierzak, 1996; Medvinsky et al., 1993; Müller et al., 1994). However, only a limited number of immortalized stromal cell lines from these embryonic hematopoietic microenvironements have been isolated and characterized (Fennie et al., 1995; Ohneda et al., 1998; Xu et al., 1998; Yoder et al., 1994; Yoder et al., 1995).

The generation of many of the stromal cell lines used in hematopoietic studies has relied on the expression of the SV40 Tag immortalizing gene (Jat and Sharp, 1986). The conditionally active form (a thermolabile form that is active at 
$33^{\circ} \mathrm{C}$ ) encoded by the $t s A 58$ gene (Tegtmeyer, 1975) has been routinely used to overcome the alteration of functional or differentiation properties sometimes associated with introduction of the SV40 Tag gene into the target cells. Most often, the $t s A 58$ gene has been introduced into cells via retrovirus-mediated transduction (Jat et al., 1986), requiring the cells of interest to divide ex vivo to achieve the integration and expression of proviral sequences. Central to the use of cell lines in the study of cellular differentiation and development is the assumption that they are representative of cells that function within the normal cellular physiology of the organism (Ridley et al., 1988). Hence, to alleviate extensive cultivation of target cells before the onset of immortalizing gene expression, transgenic mice expressing the $t s A 58$ gene have been generated.

The 'Immortomouse' (Jat et al., 1991), a transgenic mouse strain expressing the $t s A 58$ gene under the transcriptional control of the $\mathrm{H}-2 \mathrm{~K}$ promoter, has been used for the isolation of cells from many different tissues including thymus (Jat et al., 1991), colon and small intestine (Whitehead et al., 1993), gonads (Capel et al., 1996), skeletal muscle (Morgan et al., 1994) and smooth muscle (Ehler et al., 1995). To promote high levels of of $t s A 58$ expression, interferon- $\gamma$ is added during the cultivation of transgenic cells. As interferons are general activating agents and numerous investigators have demonstrated the deleterious effects of interferon- $\gamma$ on hematopoiesis (Gajewski et al., 1988; Klimpel et al., 1982; Sato et al., 1995; Selleri et al., 1995; Selleri et al., 1996), the addition of this cytokine may influence the outcome and impose a bias on the cells isolated from the hematopoietic microenvironment of the 'Immortomouse'. Hence, other transgenic mice using the SV40 transcriptional elements to direct widespread expression of the temperature-sensitive Tag gene (Yanai et al., 1991) have been generated. However, these founder chimeric transgenic mice were not bred but were used only to make primary cell lines and thus are not available for the isolation of new cell lines.

We were interested in more specifically and directly isolating hematopoietic-supportive stromal cell lines from the in vivo hematopoietic microenvironments present in the midgestation embryo. This led us to generate our own transgenic mouse lines, $\beta$-actin-tsA58 and $P G K$-tsA58, which express the thermolabile form of the SV40 Tag gene in a constitutive and ubiquitous manner. Here we present data on the isolation of over a hundred stromal cell lines from embryonic hematopoietic microenvironments. We show that expression of the $t s A 58$ transgene generally leads to the more rapid and efficient isolation of hematopoietic stromal cell populations and clones from embryonic tissues. Furthermore, these stromal cell lines are effective but heterogenous in human hematopoietic progenitor cell support. For the individual stromal clones, the hematopoietic gene expression profiles of growth factor and interleukin genes are complex, showing no obvious pattern consistent with support. However, a small subset shows high levels of transcription of the chordin-like protein gene, the protein of which is known to be a potent inhibitor of bone morphogenic proteins. Taken together, we show that stromal cells isolated from the various hematopoietic sites within tsA58 transgenic mouse embryos can be effective supporters of hematopoiesis.

\section{Materials and Methods}

\section{Generation of plasmids for transgenesis}

The NruI-BamHI human $\beta$-actin promoter fragment from plasmid pBBgeopA (from Bill Scarnes, University of California, Berkeley) was ligated with the $t s A 58$ gene (purified by BglIand ScaI digestion, blunting, and BamHI digestion of PucSV40/tsA58; gift of Parmjit Jat, Ludwig Institute, London) to generate pHAtsA58. After BglII, BamHI and $S c a$ I digestion, the purified fragment was injected into mouse oocytes.

The HindIII-BglII fragment of the $P G K$ promoter containing plasmid $\mathrm{p} P G K n e o b$ (from Austin Smith, CGR, Edinburgh, UK) was cloned into the EcoRV-BamHI fragment of SK-. This plasmid was digested with ClaI followed by blunting and SalI digestion, and the tsA58 gene (purified after BglI and ScaI digestion, blunting, and BamHI digestion of PucSV40/tsA58) was cloned downstream of the $P G K$ promoter. The fragment of $\mathrm{p}(\mathrm{P}+\mathrm{T}+\mathrm{S})$ used for injection into mouse oocytes was gel purified after digestion with $B g l I I, B a m H I$ and ScaI.

\section{Mice}

Mouse $(\mathrm{CBA} \times \mathrm{C} 57 \mathrm{BL} / 10) \mathrm{F}_{1}$ oocytes were microinjected with 5 $\mathrm{ng} / \mathrm{ml}$ of DNA, cultured overnight and implanted into pseudopregnant females as previously described (Miles et al., 1997). Founder mice and offspring were bred with $(\mathrm{CBA} \times \mathrm{C} 57 \mathrm{BL} / 10) \mathrm{F}_{1}$ mice. Hence, the isolated stromal cell lines were on a $(\mathrm{CBA} \times \mathrm{C} 57 \mathrm{BL} / 10) \mathrm{F}_{1}$ outbred background. Animals were housed according to institutional guidelines, and procedures were carried out in compliance with the Standards for Humane Care and Use of Laboratory Animals.

\section{Transgene and expression analysis}

Transgenic mice were genotyped by PCR analysis of tail DNA. PCR primer sequences are $t S A 58(\mathrm{~S}) 5^{\prime}$-tca acc tga ctt tgg agg ctt ctg- $3^{\prime}$ and tsA58(AS) 5'- gtc aca cca cag aag taa ggt tcc-3'. PCR reactions were performed at 1 cycle of $94^{\circ} \mathrm{C}$ for 4 minutes, 25 cycles of $94^{\circ} \mathrm{C}$ for 1 minute, $60^{\circ} \mathrm{C}$ for 2 minutes, $72^{\circ} \mathrm{C}$ for 2 minutes and 1 cycle of $72^{\circ} \mathrm{C}$ for 10 minutes (resultant fragment is $277 \mathrm{bp}$ ).

RNA was isolated from adult transgenic tissues using lithium chloride method (Fraser et al., 1990). cDNA was generated with Superscript II reverse transcriptase (Gibco BRL/Life Technologies, Breda, NL) and RT-PCR was performed using primers spanning the SV40 large T antigen intron to yield a specific $372 \mathrm{bp}$ fragment (genomic DNA fragment is $720 \mathrm{bp}$ ). The primer sequences were: SV40Tag(S) 5' gag ttt cat cet gat aaa gga gg $3^{\prime}$ and SV40Tag(AS) $5^{\prime}$ gtg gtg taa ata gca aag caa gc $3^{\prime}$. PCR reactions were performed at 1 cycle of $92^{\circ} \mathrm{C}$ for 5 minutes, 35 cycles of $92^{\circ} \mathrm{C}$ for 30 seconds, $60^{\circ} \mathrm{C}$ for 45 seconds, $72^{\circ} \mathrm{C}$ for 1 minute and 1 cycle of $72^{\circ} \mathrm{C}$ for 10 minutes. The GAPDH RT-PCR primers were gapdh-s $5^{\prime}$ ctt cac cac cat gga gaa gg $3^{\prime}$ and gapdh-1 5' cca ccc tgt tgc tgt agc c 3' (product $670 \mathrm{bp}$ ). Reactions were performed at 1 cycle of $92^{\circ} \mathrm{C}$ for 5 minutes, 30 cycles of $92^{\circ} \mathrm{C}$ for 1 minute, $60^{\circ} \mathrm{C}$ for 2 minutes, $72^{\circ} \mathrm{C}$ for 2 minutes and 1 cycle of $72^{\circ} \mathrm{C}$ for 10 minutes.

\section{Isolation of stromal lines and clones}

AGM, embryonic liver (EL) and gastrointestinal region (gut and mesentery; GI) cells were obtained from Tag5 (8 E11), Tag11 (7 E11 and 12 E10) and control BL1b (35 E11) transgenic embryos (Dzierzak and de Bruijn, 2002; Medvinsky and Dzierzak, 1996) (Fig. 1C). The AGM region was subdissected using $27 \mathrm{G}$ needles into the aorta, with surrounding mesenchymal tissue (AM), and the urogenital ridges, containing the pro/mesonephros and the gonads (UG) (de Bruijn et al., 2000a; de Bruijn et al., 2000b). Subdissected tissues from litters with at least seven embryos were pooled and either explant cultured at the air-medium interface on $0.1 \%$ gelatin-coated 6 -well plates 
(Costar, Badhoevedorp, NL) or cultured as a single cell suspension (after a 15 minute incubation with $0.25 \%$ trypsin and vigorous pipetting) on $0.1 \%$ gelatin-coated 6-well plates in stromal medium: $50 \%$ long-term culture medium (M5300, StemCell Technologies, Vancouver, BC, Canada), 15\% FCS, 35\% AlphaMEM, supplemented with antibiotics (penicillin and streptomycin; Gibco), Glutamax-I (Gibco) and $10 \mu \mathrm{M} \beta$-mercaptothanol (Merck Eurolab, Darmstadt, Germany). After 4 to 5 days, supernatants were collected and adherent tissues/cells harvested by brief $0.25 \%$ trypsin exposure and cultured on new dishes at a density of $5 \times 10^{4}$ cells $/ \mathrm{cm}^{2}$. Cultures were supplemented with $10-20 \% 0.2 \mu \mathrm{m}$-filtered supernatant from the previous passage each week until cell numbers increased consistently. Cells were then cloned at a density of one cell per well in $0.1 \%$ gelatin-coated 24-well plates. After 2-3 weeks clones were harvested and expanded.

Previously described stromal cell lines were used as controls for various assays: AFT024 from K. Moore (Princeton U., USA) (Moore et al., 1997a), S17 from Rudi Hendriks (Dept. of Immunology, Erasmus U., Rotterdam, NL) (Collins and Dorshkind, 1987) and MS5 from Laure Coulombel (INSERM U474, Paris, France) (Itoh et al., 1989). FBMD-1 cells were cultured as described previously (Breems et al., 1994).

\section{Production of conditioned media}

Stromal cells were grown to confluence in stromal medium. One day after reaching confluence, the supernatant was collected. This conditioned medium was further centrifuged for 7 minutes at $1,600 \mathrm{~g}$ to remove the remaining cells and debris, filtered through $0.2 \mu \mathrm{m}$ filters (Schleicher and Schüll, Dassel, Germany) and stored at $4^{\circ} \mathrm{C}$ until use.

\section{Colony forming culture analysis}

The number of murine colony-forming progenitors [colony forming culture (CFC): total of erythroid burst-forming units (BFU-E), granulocyte-erythroid-macrophage-megakaryocyte colony-forming units (CFU-GEMM) and granulocyte-macrophage colony-forming units (CFU-GM)] was determined by plating aliquots of BM cells in methylcellulose medium supplemented with pokeweed mitogenstimulated spleen cell-conditioned medium (PWM-SCM) and human erythropoietin (hu-EPO, 3 U/ml, M3430, StemCell Technologies). To investigate the growth-stimulating properties of conditioned media, BM cells were plated in methylcellulose medium with hu-EPO (M3334, StemCell Technologies) additionally supplemented with $0.22 \mu \mathrm{m}$-filtered conditioned medium harvested from confluent stromal cell cultures. Human CFC were assayed using $1.2 \%$ methylcellulose in IMDM supplemented with $30 \%$ FCS, $\beta$ mercaptoethanol $\left(10^{-4} \mathrm{M}\right)$, penicillin $(100 \mathrm{U} / \mathrm{ml})$, streptomycin $(0.1$ $\mathrm{mg} / \mathrm{ml})$, hu-EPO (1 U/ml), hu-IL3 (20 ng/ml), hu-GM-CSF (5 ng/ml), hu-G-CSF (50 ng/ml) and mu-SCF (100 ng/ml). Duplicate cultures were plated in $35 \mathrm{~mm}$ dishes (BD-Falcon) and incubated at $37^{\circ} \mathrm{C}, 10 \%$ $\mathrm{CO}_{2}$ in a humidified atmosphere for 14 days. Colonies containing more than 50 cells were scored at 10-12 days (murine CFC) or at day 14-18 (human CFC) by inverted light microscopy.

\section{RT-PCR expression analysis}

The following murine RT-PCR primer sets were used: TPO (S): tgatggcagcacgaggacagttggaa; TPO (AS): gtgaggttccagcaaagagcccatg; SCF (S): gattccagagtcagtgtcac; SCF (AS): ctggacacatgttcttgtcc; FL (S): aaagaaaaactcgagatgacagtgctggcgccagcc; FL (AS): tttgacttttaattaattactgcctgggccgaggctctgg; G-CSF (S): gacggctcgecttgctctgcacca; GCSF (AS): acctggctgccactgtttctttagg; CHL-S (S): gtcatcaataacaagcacaaac; CHL-S (AS): ggagatagaggttagatagtag; CHL-L (S): gtggagaagaaaccatgcctg; CHL-L (AS): atgtgctctataaccacctgac; $\beta$-actin (S): gtgggaattcgtcagaaggactcctatgtg; $\beta$-actin (AS): gaagtctagagcaacatagc-

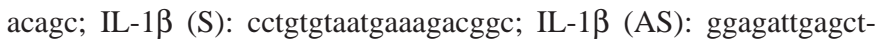
gtctgctc; IL-3 (S): gatacccaccgtttaaccagaacgttg; IL-3 (AS): tccacggttaggagagacggag; IL-6 (S): gacttcacagaggataccac; IL-6 (AS): ctccagcttatctgttaggag; IL-11 (S): agatctggacagcgctgttctctcctaa; IL-11 (AS): agtcgagtctttaacaacagcaggcc; LIF (S): cgtggagtccagtgtcttgc; LIF (AS): accgettcttcctatcacac; OSM (S): gggtctgatgacacaagctg; OSM (AS): acagagaacgctgacattcg; TGF- $\beta 1$ (S): cacagagaagaactgctgtg; TGF- $\beta 1$ (AS): aggagcgcacaatcatgttgg. RNA made from confluent layers of irradiated $(30 \mathrm{~Gy})$ stromal cell clones was used for the RTPCR analysis. $1 \mu \mathrm{g}$ of total RNA (isolated by the Trizol method) per reaction was used with a kit from Qiagen (Leusden, NL, OneStep RTPCR Kit cat\# 210212). The conditions used for TPO RT-PCR were $50^{\circ} \mathrm{C}$ for 30 minutes, $95^{\circ} \mathrm{C}$ for 15 minutes followed by 33 cycles at $94^{\circ} \mathrm{C}$ for 30 seconds and $72^{\circ} \mathrm{C}$ for 70 seconds and a final step at $72^{\circ} \mathrm{C}$ for 10 minutes (with Q buffer). For CHL-S and CHL-L RT-PCR, the conditions were $50^{\circ} \mathrm{C}$ for 30 minutes, $95^{\circ} \mathrm{C}$ for 15 minutes followed by 35 cycles at $94^{\circ} \mathrm{C}$ for 30 seconds, $60^{\circ} \mathrm{C}$ for 30 seconds and $72^{\circ} \mathrm{C}$ for 40 seconds with a final step at $72^{\circ} \mathrm{C}$ for 10 minutes (with Q buffer). For SCL, FLK-2L and G-CSF RT-PCR, the conditions were $50^{\circ} \mathrm{C}$ for 30 minutes, $95^{\circ} \mathrm{C}$ for 15 minutes followed by 33 cycles at $94^{\circ} \mathrm{C}$ for 30 seconds, $65^{\circ} \mathrm{C}$ for 30 seconds and $72^{\circ} \mathrm{C}$ for 40 seconds with a final cycle at $72^{\circ} \mathrm{C}$ for 10 minutes (no Q-buffer). The conditions for IL-1, -6 and -11 were $95^{\circ} \mathrm{C}$ for 5 minutes followed by 35 cycles at $95^{\circ} \mathrm{C}$ for 1 minute, $56^{\circ} \mathrm{C}$ for 1 minute and $72^{\circ} \mathrm{C}$ for 2 minutes with a final cycle at $72^{\circ} \mathrm{C}$ for 7 minutes; and for IL-3, OSM, LIF and TGF- $\beta 1$, the conditions were $92^{\circ} \mathrm{C}$ for 5 minutes followed by 30 cycles at $92^{\circ} \mathrm{C}$ for 45 seconds, $45^{\circ} \mathrm{C}$ for 58 seconds and $72^{\circ} \mathrm{C}$ for 1 minute with a final cycle at $72^{\circ} \mathrm{C}$ for 7 minutes.

\section{Phenotypic surface analysis of stromal cells}

Irradiated (30 Gy) stromal cells were surface phenotyped by FACS analysis. Antibodies used for FACS analysis were anti-FL and SCF (R\&D Systems, Abingdon, UK) and anti-Flk-2/Flt-3 and IL-6R $\alpha$ and Sca-1 (BD-Pharmingen, Heidelberg, Germany). Briefly, stromal cells were irradiated (30 Gy) and grown for 2 weeks under LTC-CFC assay conditions without cytokines. Cells were trypsinized, washed, stained and analyzed on a FACScan (BD-Biosciences, Erembodegem, Belgium).

\section{Extended long-term cultures of human cord blood cells on the stromal clones}

Human cord blood (CB) cells were obtained from term pregnancies with informed consent. The cells were layered upon Ficoll-Paque (density d=1.077 g/ml) and spun for 20 minutes at $600 \mathrm{~g}$, and interface cells were positively selected for the expression of CD34 using the CD34 Isolation Kit (Miltenyi Biotec, Bergisch Gladbach, Germany). The purity of the CD34-selected CB cells was $90 \pm 3 \%$.

Stromal clones were grown to confluence in $25 \mathrm{~cm}^{2}$ flasks and irradiated at 30 Gy with a ${ }^{137} \mathrm{Cs}$ source. 1 or $2 \times 10^{4} \mathrm{CD} 34^{+} \mathrm{CB}$ cells were seeded and cultured in long-term culture (LTC) medium (IMDM, 20\% FCS, penicillin (100 U/ml), streptomycin $(0.1 \mathrm{mg} / \mathrm{ml})$, $\beta$-mercaptoethanol $\left(10^{-4} \mathrm{M}\right.$, Merck), cholesterol (15 $\mu \mathrm{M}$, Sigma, Zwijndrecht, NL), linolic acid (15 $\mu \mathrm{M}$ Merck), iron-saturated human transferrin (0.62 g/l, Intergen, Uithoorn, NL), nucleic acids (cytidine, adenosine, uridine, guanosine, deoxyribonuclei 2'-deoxycytidine, 2'deoxyadenosine, thymidine, $2^{\prime}$-deoxyguanosine, all at $10^{-3} \mathrm{~g} / \mathrm{ml}$, Sigma). Initially, cells were deposited on stromal layers without cytokine supplements. However, since most stromal clones failed to support extended long-term cultures, the cultures were further supplemented by addition of thrombopoietin (TPO, $10 \mathrm{ng} / \mathrm{ml}$, Genentech, South San Fransisco, CA, USA). Flask cultures of each group were set up in duplicate and maintained at $33^{\circ} \mathrm{C}$ and $10 \% \mathrm{CO}_{2}$ for 12 weeks with weekly half medium changes and the consequent removal of half of the non-adherent cells. At weeks $7 / 8$ or 12 the total cell cultures were assayed for the level of CFC. 


\section{Results \\ Establishment of thermolabile SV40 T antigen transgenic mice}

Mice transgenic for the SV40 Tag immortalizing gene were generated for the purpose of isolating cell lines, including stromal cell lines, from embryonic hematopoietic tissues. The transgenes consist of the temperature-sensitive form (tsA58) of the SV40 Tag immortalizing gene under the control of the $\beta$ actin or $P G K$ (phosphoglycerate kinase) gene promoters, which are known to direct the ubiquitous and stable expression of transgenes in mice (Fig. 1A). Only four founder mice were obtained after pronuclear injection of the $t s A 58$ constructs into a total number of 1670 eggs. Two founders (Tag5 and Tag16) harbored the $\beta$-actin tsA58 construct. Both were healthy, but only the Tag5 founder produced transgenic offspring. Of the two founders harboring the PGK tsA58 construct (Tag 6 and Tag11), both transmitted the transgene through the germline. Although the Tag11 transgenic mouse line was healthy, the Tag6 line had marked developmental abnormalities affecting eye and bone structure. The Tag5 and Tag11 mice were maintained as heterozygotes (homozygous transgenic males of both strains were infertile) and used for all subsequent studies. Both Tag5 and Tag11 mice contain one copy of the transgene per genome as determined by Southern blot analysis (data not shown). Expression analysis by RT-PCR revealed that both lines transcribed the $t s A 58$ transgene (Fig. 1B) in all tested tissues.
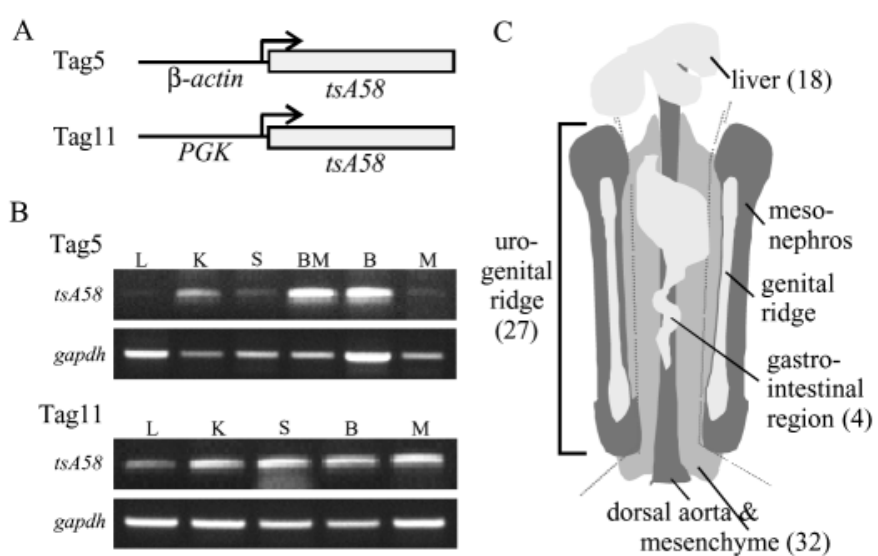

Fig. 1. SV40 T antigen transgenic mice and stromal cell generation. (A) The promoters for the constitutively and ubiquitously expressed $\beta$-actin and $P G K$ genes were cloned $5^{\prime}$ to the temperature-sensitive SV40 large T antigen (tsA58) gene. Transgenic mouse lines Tag5, containing one copy of the $\beta$-actin tsA58 gene, and Tag11, containing one copy of the $P G K$ tsA58 gene, were used to generate stromal cell lines and clones from embryonic tissues. (B) RT-PCR analysis of RNA from adult Tag5 and Tag 11 mice show expression of the $t s A 58$ transgene in all tissues tested. L, lymph nodes; K, kidney; S, spleen; BM, bone marrow, B, brain; M, muscle. (C) The embryonal subregions used for the isolation of stromal clones. E10 and E11 mouse embryos transgenic for the $t s A 58$ gene or a lacZ marker gene were used to generate stromal cell lines and clones from dorsal aorta and mesenchyme (AM), urogenital ridges (UG, mesonephros and genital ridges), the gastrointestinal region (GI) and the liver (EL). Under our culture conditions, no cell lines could be established from the yolk sac. Numbers in brackets indicate the number of clones isolated from the various subregions.

\section{Establishment of stromal cell lines from tsA58 transgenic mouse embryos}

Embryos were generated from Tag5 and Tag 11 transgenic lines and also from a control transgenic strain of mice so that we could evaluate the effects of the tsA58 gene in the isolation of stromal cell lines. We used the BL1b transgenic line as the control [(Miles et al., 1997); Ly-6E (Sca-1) lacZ transgene on (C57BL/10×CBA) outbred background], as Sca-1 is known to be expressed on most stromal lines (Montecino-Rodriguez et al., 1994). AGM regions, embryonic livers (EL), gastrointestinal tracts (GI; gut and mesentery) and yolk sacs were dissected at embryonic days 10 and 11 (E10 and E11) (Fig. 1C). Previously, it has been suggested that at these times during midgestation there may be differences in the HSC generation and supportive capacities of the aorta and surrounding mesenchyme when compared with the gonads and mesonephros (de Bruijn et al., 2000b). Thus, AGMs were subdissected into the aorta-mesenchyme (AM) and the gonadmesonephros (urogenital ridges, UG) (Fig. 1C) to examine whether functional distinctions could be identified in stromal cells isolated from these subregions.

Tissues were initially cultured at the air-medium interphase at $33^{\circ} \mathrm{C}$ on gelatin-coated culture plates containing $250 \mu \mathrm{l}$ of stroma medium, as previously these conditions provided efficient growth of HSCs in AGM explants (Medvinsky and Dzierzak, 1996). Following one day of culture, adherent cells were seen growing out of the explants. After 4 to 5 days of culture, culture supernatants were harvested and the adherent cells trypsinized and passaged at densities of $1-3 \times 10^{4} / \mathrm{cm}^{2}$ usually in the presence of $20 \%$ conditioned medium from the previous passage. In this manner, more than 28 cultures were established and grown for several months. At E11, the Tag11 line yielded one starting cell line per 1.4 embryos, and the Tag5 line yielded one starting cell line per 1.6 embryos. This is in contrast to the BL1b control transgenics, which yielded one starting cell line for every three embryos. Thus, the $t s A 58$ transgene enhances the initial in vitro establishment of cell populations from the midgestational hematopoietic sites.

Stromal cell line growth and cloning efficiency correlates with the presence of the $t s A 58$ transgene

The number of cells in the different cultures was monitored at each passage so as to determine the effect of the $t s A 58$ transgene on growth rates. Cells were passaged once a week or earlier in cases when cells were more than $90 \%$ confluent. As shown in Fig. 2, most cell populations, after the first 2 to 3 weeks of culture, regardless of whether the tsA58 transgene was present or not, underwent a crisis in which the absolute cell number decreased. This decrease persisted in the control BL1b AM-derived cultures for approximately 6-8 weeks and approximately 10 weeks in the BL1b UG-, EL- and GIderived cultures. Thereafter, cell numbers began to increase and henceforth, all post-crisis cell populations are referred to as stromal cell lines. Interestingly, increases in cell number were observed earlier for all cell lines derived from $t s A 58$ transgenic embryos and in particular from the EL (Fig. 2C). (The increase occurred up to 8 weeks earlier in $t s A 58$ EL than in BL1b EL.) In contrast, the control BL1b AM-derived cells increased their growth after 6 weeks, almost simultaneously 


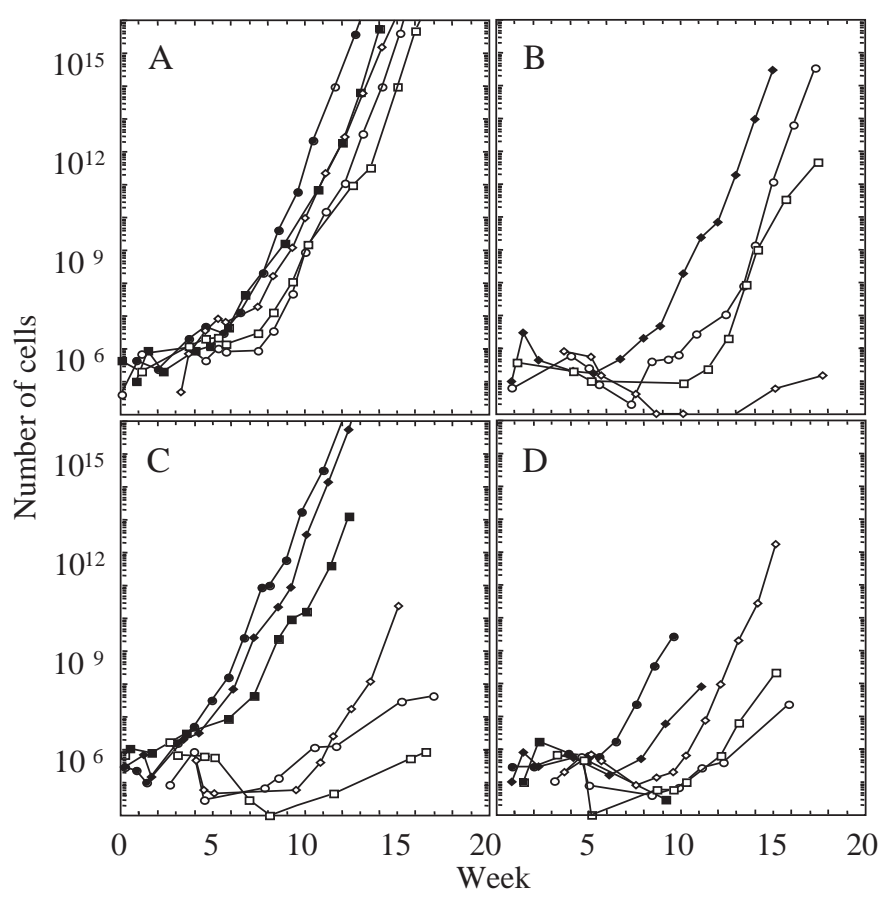

Fig. 2. Growth rate analysis of cell lines established from midgestation embryos. Cell lines were established from the (A) aorta-mesenchyme, (B) urogenital ridges, (C) embryonic liver and (D) gastrointestinal tissues of embryonic day 10 and 11 mice. The number of cells in each culture was counted at each passage, and the total number of viable cells (calculated) is plotted against time (weeks in culture after initial plating). Black-filled symbols represent cell lines derived from the $t s A 58$ transgenic embryos, and whitefilled symbols represent cell lines derived from the control lacZ transgenic embryos. All cell lines and clones established from Tag5 and Tag 11 transgenic embryos contained the $t s A 58$ transgene as determined by PCR analysis.

with the increase in $t s A 58 \mathrm{AM}$ cells, suggesting little or minor affects by the immortalizing gene in this tissue (Fig. 2A). Taken together, these data demonstrate that, with the exception of the AM, the $t s A 58$ transgene enhances the early expansion of midgestational stage embryo-derived cell populations.

When the stromal cell lines showed a consistent increase in absolute cell number for more than two passages, cloning was performed at a density of one cell per well on gelatincoated plates in the presence of $30 \%$ conditioned medium from the parental cell line. This corresponded to a time of 7 to 10 weeks after initiation of the cultures for the tsA58 transgenic tissues and between 9 to 14 weeks after initiation of the BL1b-derived tissues. In this manner, we generated 32 AM-derived clones, 27 UG-derived clones, 18 EL-derived clones, 4 GI-derived clones, as well as 12 clones from whole AGM regions (Fig. 1C). Although a large number of clones were derived from tsA58 cell lines, several were obtained from the BL1b cell lines. The cloning efficiencies of cells originating from each transgenic line are $3.5 \%$ for BL1b, $9 \%$ for Tag5 and $13-15 \%$ for Tag 11 . These results demonstrate that the $t s A 58$ transgene not only increases the growth rate but also the cloning efficiencies of stromal cells from the midgestation embryo.
Table 1. Stimulation of CFC growth with stromal cell line supernatants

\begin{tabular}{|c|c|c|}
\hline Stromal line & $\begin{array}{l}\mathrm{CFC} / 10^{4} \mathrm{BM} \\
\text { cells } \pm \text { s.e.m. }\end{array}$ & $\begin{array}{l}\text { Percentage of PWM } \\
\text { control } \pm \text { s.e.m. }\end{array}$ \\
\hline AM06 & $32.3 \pm 5.7$ & $40.6 \pm 7.2$ \\
\hline $\mathrm{AM} 10^{\dagger}$ & $54.3 \pm 3.5$ & $68.2 \pm 4.4$ \\
\hline AM14 & $33.0 \pm 6.4$ & $41.5 \pm 8.1$ \\
\hline AM20* & $72.3 \pm 4.7$ & $90.9 \pm 5.9$ \\
\hline AM30 & $49.3 \pm 4.5$ & $61.9 \pm 5.7$ \\
\hline $\mathrm{UG} 7^{\dagger}$ & $55.0 \pm 4.6$ & $69.2 \pm 5.8$ \\
\hline $\mathrm{UG}_{1} 5^{\dagger}$ & $32.5 \pm 2.1$ & $40.9 \pm 2.6$ \\
\hline UG26 & $61.8 \pm 2.6$ & $77.7 \pm 3.3$ \\
\hline $\mathrm{ELO}^{\dagger}$ & $61.0 \pm 5.1$ & $76.7 \pm 6.4$ \\
\hline EL12 ${ }^{\dagger}$ & $19.0 \pm 2.9$ & $23.9 \pm 3.6$ \\
\hline EL17*,† & $48.3 \pm 2.8$ & $60.7 \pm 3.5$ \\
\hline EL23 & $47.5 \pm 2.7$ & $59.7 \pm 3.4$ \\
\hline EL28 & $44.3 \pm 4.6$ & $55.7 \pm 5.8$ \\
\hline AFT024 & $35.8 \pm 2.8$ & $45.0 \pm 3.5$ \\
\hline FBMD-1 & $37.5 \pm 2.8$ & $47.2 \pm 3.5$ \\
\hline S17 & $46.8 \pm 2.1$ & $58.8 \pm 2.6$ \\
\hline
\end{tabular}

Four experiments were carried out. *Stromal lines derived from E10 tissue. All other stromal lines are derived from E11 tissues. ${ }^{\dagger}$ Stromal lines derived from BL1b transgenic embryos. All other stromal lines are derived from tsA58 transgenic embryos. Culture supernatants were collected from nonirradiated cells.

Conditioned medium from stromal cell lines promotes the differentiation and growth of hematopoietic colonies

Since the stromal cell lines were isolated from several midgestational hematopoietic sites and each site is known to harbor functionally different but some overlapping sets of hematopoietic cells, it was of interest to first examine which lines produced hematopoietic growth factors. Cell line supernatants were harvested and tested for CFC-promoting activity on adult BM cells in methylcellulose cultures. As shown in Table 1, all the tested stromal cell lines from the AM, UG and EL produced conditioned medium capable of supporting the differentiated growth of CFCs. On average, the AM-derived lines stimulated $48.2 \mathrm{CFC} / 10^{4} \mathrm{BM}$ cells $(n=5)$, UG-derived lines stimulated $49.8 \mathrm{CFC} / 10^{4} \mathrm{BM}$ cells $(n=3)$ and EL-derived lines stimulated $44.0 \mathrm{CFC} / 10^{4} \mathrm{BM}$ cells $(n=5)$. No correlation was observed between activity and tissue origin or the presence of the $t s A 58$ transgene. Also, the activity in the supernatants of these stromal cell lines was similar to supernatants isolated from other previously published stromal clones: AFT024 [E14.5 EL-derived (Moore et al., 1997a)] stimulated $35.8 \mathrm{CFC} / 10^{4} \mathrm{BM}$ cells, FBMD-1 [adult BMderived (Breems et al., 1994)] stimulated $37.5 \mathrm{CFC} / 10^{4} \mathrm{BM}$ cells and S17 [adult BM-derived (Collins and Dorshkind, 1987)] stimulated $46.8 \mathrm{CFC} / 10^{4} \mathrm{BM}$ cells.

In addition, conditioned media obtained from stromal clones was measured using the CFC assay (Table 2). All tested stromal clones produced conditioned medium with a similar level of activity to the starting stromal lines. With the exception of one AM-derived line and clone, none of the stromal lines or clones surpassed the number of CFCs yielded by the PWMSCM control. The AM20 line and its derived clone AM20-1A4 consistently produced the highest numbers of CFCs (72.3 and 83.5 CFC/104 BM cells, respectively) and yielded 90.9-105.5\% and $114.0 \%$ activity (respectively) of the PWM-SCM control, suggesting that these cells elaborate an abundance of 
Table 2. Stimulation of CFC growth with stromal clone supernatants

\begin{tabular}{lcc}
\hline Stromal clones & $\begin{array}{c}\text { CFC/10 } \\
\pm \text { s.e.m. }\end{array}$ & $\begin{array}{c}\text { Percentage of PWM } \\
\text { control } \pm \text { s.e.m. }\end{array}$ \\
\hline AM14.1C4 & $52.8 \pm 1.9$ & $72.0 \pm 2.6$ \\
AM20.1A4* & $83.5 \pm 4.5$ & $114.0 \pm 6.1$ \\
AM30.1C6 & $40.5 \pm 3.5$ & $55.3 \pm 4.8$ \\
AM30.2A4 & $52.5 \pm 1.5$ & $71.7 \pm 2.0$ \\
AM30.2B4 & $43.5 \pm 1.5$ & $59.4 \pm 2.0$ \\
AM30.3A3 & $48.5 \pm 5.5$ & $66.2 \pm 7.5$ \\
AM30.3E8 & $39.5 \pm 9.5$ & $53.9 \pm 13.0$ \\
AM30.3F4 & $46.0 \pm 1.0$ & $62.8 \pm 1.4$ \\
UG15.1B7 & $47.0 \pm 1.0$ & $64.2 \pm 1.4$ \\
EL23.1C5 & $39.5 \pm 8.0$ & $53.9 \pm 10.9$ \\
EL23.1C6 & $21.5 \pm 2.5$ & $29.4 \pm 3.4$ \\
EL23.2A2 & $50.3 \pm 4.1$ & $68.6 \pm 5.6$ \\
EL23.2D3 & $46.5 \pm 0.5$ & $63.5 \pm 0.7$ \\
EL28.1B3 & $56.5 \pm 11.0$ & $77.1 \pm 15.0$ \\
EL28.1D3 & $46.5 \pm 0.5$ & $63.5 \pm 0.7$ \\
EL28.2B2 & $39.0 \pm 4.0$ & $53.2 \pm 5.5$ \\
AM20 & $77.3 \pm 4.2$ & $105.5 \pm 5.7$ \\
& &
\end{tabular}

These are the results of between two and four experiments. *Stromal clones derived from E10 tissue. All other stromal clones derived from E11 tissues. $\dagger$ Stromal clones derived from BL1b transgenic embryos. All other stromal clones are derived from $t s A 58$ transgenic embryos. Culture supernatants were collected from non-irradiated cells.

hematopoietic growth factors. The AM20 and AM20-1A4 supernatants also promoted outgrowth of the different types of CFC (BFU-E, GEMM-CFC and GM-CFC), comparable to PWM-SCM (data not shown). In contrast to the other stromal cells derived from E11 tissues, the AM20 line was derived from an E10 AM subregion. Thus, despite the visible absence of hematopoietic differentiation in vivo in the E10 and E11 AGM region, AGM-derived stromal cells are able to produce conditioned medium that support the in vitro growth of BMderived CFCs.

\section{Stromal support for primitive progenitor cells in human extended long-term co-cultures}

To examine the ability of embryonic stromal clones to support the sustained generation of primitive hematopoietic progenitors, we tested the CFC production from human CD34+ cord blood cells co-cultured for 7 or 8 (7/8) and 12 days with irradiated stromal clones. Pilot experiments demonstrated that in the absence of growth factors, neither the clones nor FBMD1 or AFT024 control cells supported sustained CFC or cobblestone-area-forming cell production (data not shown). (N.K., R.A.J.O. and W. J. L. M. Koevoet et al., unpublished). In the presence of TPO, several embryonic stromal clones (AM06-2C4, AM20-1B4, UG15-1B7, UG26-2D3 and EL231C2) still failed to support sustained progenitor production (Table 3). However, UG26-1B4, UG26-3D4, AM30-2A4, $\mathrm{AM} 30-3 \mathrm{~A} 3$ and $\mathrm{AM} 30-3 \mathrm{~F} 4$ maintained the number of hematopoietic progenitors in the adherent compartment (an expansion between half- and threefold). Several other clones (AM30-1C6, UG26-1B6, GI09-2E6 and GI29-2B4) supported a net expansion of CFC comparable to the control cells. FBMD-1 and AFT024 showed a fourfold and twofold expansion after $7 / 8$ and 12 weeks, respectively. Interestingly,
Table 3. Long-term support of human adherent CFC production

\begin{tabular}{|c|c|c|c|c|}
\hline \multirow[b]{3}{*}{ Stromal cells } & \multicolumn{4}{|c|}{ Fold increase in input CFCs } \\
\hline & \multicolumn{2}{|c|}{$7 / 8$ week culture } & \multicolumn{2}{|c|}{12 week culture } \\
\hline & ТPO & $\mathrm{TPO}+\mathrm{FL}$ & ТРО & $\mathrm{TPO}+\mathrm{FL}$ \\
\hline FBMD-1 & 3.7 & 3.8 & 1.4 & 2.4 \\
\hline AFT024 & 4.8 & 5.2 & 2.4 & 3.4 \\
\hline AM06-1C4 & 0.1 & 0.6 & nd & nd \\
\hline AM06-2C4 & 0.3 & 0.7 & 0.0 & 0.0 \\
\hline AM20-1A4 & 2.9 & 1.3 & nd & nd \\
\hline AM20-1B4 & 0.0 & 0.0 & 0.0 & 0.0 \\
\hline AM30-1C6 & 3.6 & 2.5 & 0.9 & 0.5 \\
\hline AM $30-2 A 4$ & 1.9 & 0.3 & 0.3 & 0.3 \\
\hline AM30-3A3 & 0.9 & 0.1 & 0.4 & 0.3 \\
\hline AM30-3F4 & 1.9 & 2.3 & 0.6 & 0.9 \\
\hline AM30-3F5 & 0.9 & 0.0 & nd & 1.1 \\
\hline UG07-1C6* & 0.6 & 2.7 & nd & nd \\
\hline UG15-1B7* & 0.0 & 0.0 & 0.0 & 0.0 \\
\hline UG26-1B4 & 1.3 & 3.3 & 0.5 & 0.3 \\
\hline UG26-1B6 & 2.2 & 5.0 & 1.1 & 2.3 \\
\hline UG26-2D3 & 0.1 & nd & 0.0 & 0.0 \\
\hline UG26-3D4 & 1.5 & nd & 0.3 & 1.3 \\
\hline EL08-1D2* & 9.1 & 11.8 & 11.4 & 12.6 \\
\hline EL23-1C2 & 0.9 & 0.5 & 0.0 & nd \\
\hline GI09-2E6* & 1.8 & 1.3 & 0.9 & 0.8 \\
\hline GI29-2B4 & 2.3 & 4.2 & 1.1 & 2.3 \\
\hline
\end{tabular}

Human cord-blood-derived CD $34^{+}$cells were cultured on irradiated embryonic stromal cells in the presence of TPO or a combination of TPO and FL. Data represent the CFC content of the adherent layers in the extended LTC as measured on weeks $7 / 8$ and 12 as the fold increase in the input population of cells. The input, uncultured material contained $1.8 \pm 1.0 \times 10^{4}$ CFC per $10^{5} \mathrm{CD} 34^{+}$human CB cells. LTC were maintained by weekly change of the half medium with removal of half of the non-adherent cells in the presence of added TPO $(10 \mathrm{ng} / \mathrm{ml})$ or a combination of TPO and Flt3ligand $(\mathrm{FL}, 50 \mathrm{ng} / \mathrm{ml})$. At the designated culture time, the adherent layers were washed twice with serum-free medium and trypsinized. AM, aortamesenchyme; UG, urogenital ridges; GI, gastrointestinal tract; EL, embryonic liver. *Stromal clones derived from BL1b transgenic embryos. All other stromal clones were derived from $t s A 58$ transgenic embryos. The lines UG261B6, GI29-2B4 and EL08-1D2 score similarly overall or even better than the control cell lines FBMD-1 and AFT024. Data represent the mean of one to three independent experiments each containing four cultures per group. nd, not determined.

EL08-1D2 supported a tremendous expansion of hematopoietic progenitors in the adherent layer of more than 9- and 12-fold under similar conditions at weeks $7 / 8$ and 12 after culture, respectively (Table 3 ). Thus, stromal clones from several different murine embryonic sites support human hematopoiesis.

\section{Characterization of stromal clones for growth factor mRNA expression}

Since several of the embryonic stromal clones were capable of supporting the in vitro hematopoietic differentiation of human progenitors and the maintenance of murine stem cells (Oostendorp et al., 2002), we tested and compared the relative levels of expression of growth factors thought to be important in hematopoiesis using RT-PCR. We also measured the expression of the recently described chordin-like protein (CHL) in the short and long forms (-S and -L), which are inhibitors of bone morphogenetic proteins and are preferentially expressed in mesenchymal cells (Nakayama et al., 2001). 
Table 4. Hematopoietic growth factor semi-quantitative RT-PCR expression analysis of embryonic and control stromal clones

\begin{tabular}{|c|c|c|c|c|c|c|c|c|c|c|c|c|c|c|}
\hline & $\begin{array}{l}\text { TPO } \\
516^{\dagger}\end{array}$ & $\begin{array}{l}\text { SCF } \\
586\end{array}$ & $\begin{array}{l}\text { FL } \\
603\end{array}$ & $\begin{array}{c}\text { G-CSF } \\
515\end{array}$ & $\begin{array}{c}\text { CHL-S } \\
979\end{array}$ & $\begin{array}{c}\text { CHL-L } \\
750\end{array}$ & $\begin{array}{c}\text { IL-1 } \beta \\
330\end{array}$ & $\begin{array}{c}\text { IL-3 } \\
400\end{array}$ & $\begin{array}{c}\text { IL-6 } \\
420\end{array}$ & $\begin{array}{c}\text { IL-11 } \\
485\end{array}$ & $\begin{array}{l}\text { LIF } \\
520\end{array}$ & $\begin{array}{c}\text { OSM } \\
350\end{array}$ & $\begin{array}{c}\text { TGF- } \beta 1 \\
295\end{array}$ & $\beta$-actin \\
\hline FBMD-1 & 2 & 4 & 3 & 4 & 2 & 3 & 0 & 0 & 1 & 1 & 1 & 0 & 2 & 3 \\
\hline M2-10B4 & 2 & 3 & 3 & 3 & 0 & 2 & nd & nd & nd & nd & nd & nd & nd & 3 \\
\hline MS-5 & 3 & 4 & 3 & 4 & 0 & 2 & nd & nd & nd & nd & nd & nd & nd & 3 \\
\hline AM14-1C4* & 2 & 3 & 2 & 3 & 3 & 3 & 2 & 0 & 2 & 2 & 0 & 0 & 3 & 3 \\
\hline AM20-6B4 & 0 & 1 & 1 & 0 & 0 & 1 & nd & nd & nd & nd & nd & nd & nd & 3 \\
\hline AM20-3C3 & 0 & 3 & 2 & 2 & 0 & 1 & nd & nd & nd & nd & nd & nd & nd & 3 \\
\hline AM30-1C6 & 3 & 2 & 1 & 1 & 0 & 1 & nd & nd & nd & nd & nd & nd & nd & 3 \\
\hline AM30-2A4 & 0 & 3 & 1 & 1 & 0 & 1 & 1 & 0 & 2 & 0 & 0 & 0 & 1 & 3 \\
\hline AM30-3A3 & 2 & 1 & 1 & 1 & 0 & 1 & 2 & 0 & 2 & 0 & 1 & 0 & 0 & 3 \\
\hline AM30-3E8 & 2 & 1 & 0 & 0 & 0 & 1 & 1 & 0 & 0 & 0 & 0 & 0 & 0 & 3 \\
\hline AM30-3F4 & 2 & 3 & 2 & 2 & 2 & 2 & 1 & 0 & 1 & 2 & 0 & 0 & 3 & 3 \\
\hline AM30-3F5 & 3 & 2 & 0 & 2 & 0 & 0 & 0 & 0 & 1 & 1 & 0 & 0 & 0 & 3 \\
\hline UG07-1C6* & 3 & 1 & 1 & 1 & 0 & 0 & nd & nd & nd & nd & nd & nd & nd & 3 \\
\hline UG15-1B7* & 0 & 1 & 0 & 0 & 0 & 0 & nd & nd & nd & nd & nd & nd & nd & 1 \\
\hline UG26-1B4 & 0 & 2 & 1 & 1 & 2 & 2 & nd & 0 & nd & nd & 1 & 0 & 2 & 3 \\
\hline UG26-1B6 & 2 & 3 & 1 & 2 & 2 & 2 & 2 & 0 & 3 & 0 & 1 & 0 & 3 & 3 \\
\hline UG26-2B3 & 2 & 2 & 1 & 2 & 0 & 0 & nd & 0 & nd & nd & 2 & 0 & 3 & 3 \\
\hline UG26.3B5 & nd & nd & nd & nd & nd & nd & 0 & 0 & 2 & 1 & 2 & 0 & 3 & nd \\
\hline UG26-2D3 & 3 & 3 & 1 & 2 & 3 & 3 & 1 & 0 & 3 & 2 & 0 & 0 & 1 & 3 \\
\hline UG26-3D4 & 1 & 3 & 1 & 2 & 0 & 1 & 2 & 0 & 3 & 1 & 1 & 0 & 2 & 3 \\
\hline EL08-1D2* & 3 & 3 & 3 & 2 & 3 & 3 & 0 & 0 & 2 & 0 & 0 & 0 & 1 & 3 \\
\hline EL08-2C2* & 1 & 2 & 1 & 2 & 1 & 1 & 1 & 0 & 0 & 0 & 0 & 0 & 0 & 3 \\
\hline EL23-1B4 & 2 & 3 & 2 & 2 & 1 & 1 & nd & nd & nd & nd & nd & nd & nd & 3 \\
\hline EL28-1B3 & 2 & 2 & 1 & 2 & 0 & 1 & nd & nd & nd & nd & nd & nd & nd & 3 \\
\hline GI09-2E6** & 2 & 2 & 1 & 2 & 3 & 3 & 1 & 0 & 1 & 1 & 2 & 0 & 3 & 3 \\
\hline GI29-2B4 & 1 & 2 & 1 & 1 & 0 & 0 & 0 & 0 & 2 & 1 & 3 & 0 & 3 & 3 \\
\hline
\end{tabular}

*Stromal clones derived from BL1b transgenic embryos. All other stromal clones are derived from $t$ sA58 transgenic embryos. ${ }^{\dagger}$ Fragment size of RT-PCR product. Signal intensity: 4, extremely high; 3, high; 2 , intermediate; 1, low; 0, no expression; nd, not determined. RNA was prepared from non-irradiated stromal cells, and normalization with $\beta$-actin signal was performed for TPO, SCF, FL, G-CSF, CHL-S and -L RT-PCRs. RNAs for the remaining RT-PCRs were from irradiated stromal clones, and the GAPDH signal (not shown) was used for normalization. Signal intensities were compared only within a PCR set and not between PCR sets.

In the first experiments, mRNA isolated from 22 stromal (non-irradiated) clones was analysed for the expression of thrombopoietin (TPO), stem cell factor (SCF), Flk-2 ligand (FL), granulocyte-colony stimulating factor (G-CSF) and CHL-S and -L genes in a semi-quantitative manner. As shown in Table 4, most of the stromal clones expressed TPO, SCF and G-CSF mRNA to varying levels. TPO and SCF were expressed from high to intermediate levels in 14/22 and 17/22 of the clones, respectively. G-CSF was expressed predominantly at intermediate levels (12/22 of the clones). In contrast, the Flk2 ligand was expressed only at a low level in 14/22 of the clones. For comparison, in adult marrow-derived stromal cell lines (FBMD-1, M2-10B4, and MS-5), the expression of TPO, SCF, G-CSF and FL was high. But, all in all, no overall consistent pattern of expression was observed for this panel of molecules within the stromal clones tested. However, a restricted high-level expression (both forms) of the $C H L$ gene was observed in $4 / 22$ of the stromal clones tested. A further three clones expressed CHL to intermediate levels and 13 clones expressed no CHL-S and only low level or no expression of CHL-L. The expression patterns do not correlate with derivation from a specific embryonic day, tissue or transgenic line. The three marrow-derived lines all expressed the long form of CHL, but the short form was only observed in FBMD-1.

Additionally, we examined 15 embryonic stromal clones for their expression of growth factors IL-1, -3, -6, -11, LIF, Oncostatin M and TGF- $\beta 1$ by RT-PCR after irradiation (since the clones were irradiated in the hematopoietic support experiments). As shown in Table 4, varying expression patterns were observed. Consistently, we found that the stromal clones did not express detectable levels of IL-3 and Oncostatin M (OSM) transcripts, even though cDNA controls (WEHI 3 for IL-3 and fetal liver for OSM) were strongly positive. IL-1, IL11 and LIF expression was found in only a few of the clones, whereas most of the stromal clones expressed IL-6 and TGF$\beta 1$. Taken together with CFC data, no correlation can be found between expression patterns and supernatants promoting hematopoietic growth. Thus, the clones tested exhibit a heterogeneous pattern of growth factor expression on the mRNA level.

\section{Surface phenotype of stromal cells}

FACS analysis was performed on a small number of irradiated stromal clones (chosen for their ability to support sustained CFC production) and the control, FBMD-1, to determine whether some growth factors and growth factor receptor proteins were produced and elaborated on the cell surface. As in the co-cultures, the lines were irradiated and grown in LTC medium. FACS analysis revealed SCF expression at low levels on the surface of one of the clones, AM20-1B4 (Table 5). Only GI29-2B4 was found to express the FL. None of the clones expressed the Flk-2 receptor tyrosine kinase. However, IL-6R $\alpha$ expression was found on six out of six of the tested clones. In addition, all of the lines, including FBMD-1, strongly 
Table 5. Surface molecule expression on stromal clones

\begin{tabular}{lccccc}
\hline Clone & SCF & FL & Flk-2 & IL-6R $\alpha$ & Sca-1 \\
\hline FBMD-1 & - & - & - & nd & + \\
AM06.1C4* & - & - & - & + & + \\
AM20.1B4 & + - & - & - & + & + \\
UG15.1B7* & - & - & - & + & + \\
UG26.1B6 & - & - & - & + & + \\
EL08.1D2* & - & - & - & + & + \\
GI29.2B4 & - & +- & - & + & +
\end{tabular}

Irradiated stromal cells were immunostained and analyzed using a FACS scan. Cells considered positive (+) contained greater than $10 \%$ of cells expressing these antigens. $+/-$ indicates that between 1 and $5 \%$ of the cells expressed the antigen. Negative (-) indicates that no or less than $1 \%$ of cells expressed the antigen. Analysis was performed at least three times on irradiated cells. *Stromal clones were derived from BL1b transgenic embryos. All other stromal clones are derived from $t s A 58$ transgenic embryos. nd, not determined.

expressed the Sca-1 antigen, a marker expressed on all supportive stromal cell lines (Rémy-Martin et al., 1999). Taken together, these limited protein expression data do not correlate with site of origin of the stromal clone or the presence of the tsA58 transgene and support the notion that the isolated stromal clones are heterogeneous.

\section{Discussion}

We have shown here that it is possible to isolate a large panel of hematopoietic stromal clones from the earliest stages of HSC appearance in E10 and E11 mouse embryos and in particular from distinct ontogenic sites. Owing to the limited number of cells available from these subdissected embryonic tissues and the low frequency of spontaneous cell immortalization in culture, we used the SV40 tsA58 immortalizing gene to aid in stromal cell isolation. The SV40 Tag gene has been used as an immortalizing agent for many years. Its immortalizing activity is based upon its interaction with the retinoblastoma protein and p53, and their regulators $\mathrm{p} 21^{\mathrm{CIP} 1 / \mathrm{WAF} 1}$ and $\mathrm{p} 16^{\mathrm{INK} 4}$, and the recently described tumor suppressor gene SEN6 leading to extended proliferation (Smith and Pereira-Smith, 1996). Rather than using the commercially available 'Immorto' mouse (Jat et al., 1991) or the transient transgenic approach (Okuyama et al., 1995a; Okuyama et al., 1995b), we generated two new mouse lines, Tag5 and Tag11, that express the $t s A 58$ gene under the control of the $\beta$-actin or $P G K$ gene promoters.

In the numerous fertilized mouse eggs microinjected with $\beta$-actin- and PGK-tsA58 constructs, we found a low frequency of transgenesis. Although it is clear that construct preparation, the quality of the eggs and the injection procedure play an important role in the success of transgenesis, we were able to produce only four transgenic founders. One founder did not pass the transgene through the germline, and one had severe eye and skeletal problems. Thus, the $t s A 58$ protein may have some debilitating effects in vivo both at developmental and adult stages. It is possible that areas of lower temperature (i.e. testis, long bones) could promote activation of the $\mathrm{T}$ antigen protein and result in abnormal cell function. Additionally, alterations in expression levels caused by the site of transgene integration and/or the specific sites of $\mathrm{T}$ antigen protein production may play a role in such abnormalities. The result that only low copy numbers were found in the two established transgenic lines, together with the low efficiency of transgenic founder generation, strongly suggests that high copy number/high expression levels are prohibitive for viability.

The presence of the $t s A 58$ gene leads to more efficient stromal cell line and clone isolation from embryonic tissues, except for the aorta-mesenchyme

We have demonstrated that the use of $\beta$-actin and PGK-tsA58 transgenic mice was instrumental in the efficient isolation of so many lines from early midgestation embryos. By direct comparison, twice as many lines were isolated from the $t s A 58$ transgenic embryos than from the control lac $Z$ transgenic embryos. Furthermore, the presence of the $t s A 58$ gene allowed for a three- to four-fold greater cloning efficiency compared with control lacZ marker transgenics. Although the limiting dilution culture step assured us that our stromal cells were clonal (yielding morphologically divergent clones as compared with the initial lines), in some cases the initial lines may already have been clonal.

Although the $t s A 58$ gene had an enhancing effect on the growth of EL-, UG- and GI-derived cell lines, it did not affect the growth of AM-derived lines. What is most intriguing is that this subregion undergoes such a short crisis phase, followed by rapid growth. The cells from the AM may be already undergoing such a high rate of proliferation that their growth could not be further increased by $t s A 58$. Our preliminary data with in vivo BrdU labeling of embryos suggests that the cells of the AM are undergoing rapid proliferation (E.D., unpublished). Thus, with an interest in understanding the generation and expansion of the hematopoietic system in the AGM region, the molecular basis of the high proliferation rate of AM-derived cells will be further examined.

\section{Most embryonic stromal cell lines and clones express hematopoietic growth factors}

By analyzing the supernatants of the stromal cell lines, we were able to determine that all the isolated cell lines and clones do have hematopoiesis-promoting activity, with the E10 AMderived line AM20 producing the most effective conditioned medium. RNA and/or FACS analysis revealed that most of the stromal clones tested expressed a panel of hematopoietic growth factors. All of our clones were positive for SCF transcripts. However, FACS analysis showed detectable SCF protein on only one out of the six clones tested, suggesting that the majority of clones secrete SCF, which is known to be important for the migration, proliferation and/or differentiation of early hematopoietic progenitors. And although most of the clones expressed TPO RNA, we found no surface-bound TPO (data not shown), suggesting that a secreted form may provide support for HSCs, which are known to express c-mpl, the receptor for TPO (McKinstry et al., 1997). Future studies will test for support of HSCs by our stromal clones in non-contact cultures. Similar to the previously published AGM stromal clones (Ohneda et al., 1998; Xu et al., 1998), our clones exhibited variable expression of IL-11 and LIF, low expression of IL-1 and no expression of IL-3 and OSM. Contrasting with the three published AGM stromal clones (Ohneda et al., 1998; 
Xu et al., 1998), most of our stromal clones were positive for G-CSF RNA. Finally, the expression patterns of TGF- $\beta 1$ and $\mathrm{CHL}$ in our stromal clones are the most intriguing. TGF- $\beta 1$ was thought to have a strong negative influence on the growth of HSCs. Surprisingly, we found high levels of TGF- $\beta 1$ expression in most of our stromal clones, even in the supportive clones. However, in some of the clones we also found expression of the $C H L$ gene (both forms). The CHL protein is thought to inhibit the negative effects of BMP-4 and TGF $\beta$ molecules on hematopoietic cells (Nakayama et al., 2001). Hence, the appropriate balanced expression of these molecules in the stromal clones may be important for hematopoieticsupportive properties, and future experiments should examine such interactions.

\section{Stromal clones supporting human hematopoietic progenitors express most hematopoietic growth factors}

In functional studies examining the long-term support of human hematopoietic progenitors, we found a few stromal clones from each of the embryonic hematopoietic subregions to be highly active: AM-derived AM30-1C6 and AM30-3F4, urogenital-ridge-derived UG26-1B4 and UG26-1B6, gastrointestine-derived GI09-2E6 and GI29-2B4 and the embryonic liver-derived EL-08-1D2, which is the best, supporting three- to five-fold expansion of CFC production in 12 week cultures supplemented with FL and/or TPO (Table 3). In related studies characterizing the stromal cell support for murine progenitors and HSCs (Oostendorp et al., 2002), we found that most of these clones also support the long-term maintenance of adult BM-enriched murine HSCs and that the second best supporter of human CFC production, UG26-1B6, is best at maintaining murine HSC activity (Oostendorp et al., 2002). Interestingly, five out of the seven clones listed above express both forms of the $C H L$ gene. Thus, when compared against the expression profiles, there appears to be a correlation between widespread, high-level growth factor/CHL transcription and long-term support for human and mouse hematopoietic progenitors.

In conclusion, the Tag5 and Tag11 transgenic lines of mice have been instrumental in the isolation of numerous hematopoietic stromal cells to further our studies of the midgestational hematopoietic microenvironment. We have shown here that these each of the subregions yields hematopoietic supportive stromal clones and that they transcribe an abundance of hematopoietic growth factors. A general trend in expression profiles suggests that widespread, high level transcription of at least some of these factors is necessary for hematopoietic support. In future studies these stromal clones will serve as the basis for comparative microarray screening to further evaluate the complex panel of genes necessary for the growth and maintenance of hematopoietic progenitors.

We thank D. Abraham and members of the laboratory for helpful discussions and assistance. We appreciate the assistance of $\mathrm{B}$. Dortland and L. Braam in mouse breeding, C. Miles for BL1b mice, D. Meijer for molecular expertise and Min Xia for help with RT-PCR. We thank P. Jat, W. Skarnes and A. Smith for plasmids, K. Moore for AFT024 and R. Hendriks for S17. This work was supported by the Netherlands Research Organization 901-08-090 (E.D.), National Institutes of Health R01 DK51077 (E.D.), Netherlands Cancer Society
(N.K.B.) EUR 1999-1965 (E.D.), Erasmus U. Breedtestrategie (KH) and Amgen, Thousand Oaks, CA (T.C., C.S. and E.D.) and Human Scientific Frontier Program RG0345/1999M (C.O.). A.M. is a Senior MRC fellow.

\section{References}

Baum, C. M., Weissman, I. L., Tsukamoto, A. S., Buckle, A. M. and Peault, B. (1992). Isolation of a candidate human hematopoietic stem-cell population. Proc. Natl. Acad. Sci. USA 89, 2804-2808.

Breems, D. A., Blokland, E. A., Neben, S. and Ploemacher, R. E. (1994). Frequency analysis of human primitive haematopoietic stem cell subsets using a cobblestone area forming cell assay. Leukemia 8, 1095-1104.

Capel, B., Hawkins, J. R., Hirst, E., Kioussis, D. and Lovell-Badge, R. (1996). Establishment and characterization of conditionally immortalized cells from the mouse urogenital ridge. J. Cell Sci. 109, 899-909.

Collins, L. S. and Dorshkind, K. (1987). A stromal cell line from myeloid long-term bone marrow cultures can support myelopoiesis and B lymphopoiesis. J. Immunol. 138, 1082-1087.

de Bruijn, M., Peeters, M., Luteijn, T., Visser, P., Speck, N. and Dzierzak, E. (2000a). CFU-S 11 activity does not localize solely with the aorta in the AGM region. Blood 96, 2902-2904.

de Bruijn, M. R. T. R., Speck, N. A., Peeters, M. C. E. and Dzierzak, E. (2000b). Definitive hematopoietic stem cells first emerge from the major arterial regions of the mouse embryo. EMBO J 19, 2465-2474.

Deryugina, E. I., Ratnikov, B. I., Bourdon, M. A. and Muller-Sieburg, C. E. (1994). Clonal analysis of primary marrow stroma: functional homogeneity in support of lymphoid and myeloid cell lines and identification of positive and negative regulators. Exp. Hematol. 22, 910918 .

Dzierzak, E. and de Bruijn, M. (2002). Isolation and analysis of hematopoietic stem cells from mouse embryos. In Methods in Molecular Medicine: Hematopoietic Stem Cell Protocols (ed. C. Klug and C. Jordan), pp. 1-14. Totowa: The Humana Press Inc.

Dzierzak, E., Medvinsky, A. and de Bruijn, M. (1998). Qualitative and quantitative aspects of haemopoietic cell development in the mammalian embryo. Immunol. Today 19, 228-236.

Ehler, E., Jat, P. S., Noble, M. D., Citi, S. and Draeger, A. (1995). Vascular smooth muscle cells of $\mathrm{H}-2 \mathrm{~Kb}$-tsA58 transgenic mice. Characterization of cell lines with distinct properties. Circulation 92, 3289-3296.

Fennie, C., Cheng, J., Dowbenko, D., Young, P. and Lasky, L. A. (1995). CD34+ endothelial cell lines derived from murine yolk sac induce the proliferation and differentiation of yolk sac CD34+ hematopoietic progenitors. Blood 86, 4454-4467.

Fraser, P., Hurst, J., Collis, P. and Grosveld, F. (1990). DNaseI hypersensitive sites 1, 2 and 3 of the human beta-globin dominant control region direct position-independent expression. Nucleic Acids Res. 18, 35033508 .

Gajewski, T. F., Goldwasser, E. and Fitch, F. W. (1988). Anti-proliferative effect of IFN-gamma in immune regulation. II. IFN-gamma inhibits the proliferation of murine bone marrow cells stimulated with IL-3, IL-4, or granulocyte-macrophage colony-stimulating factor. J. Immunol. 141, 26352642.

Godin, I., Garcia-Porrero, J. A., Dieterlen-Lievre, F. and Cumano, A. (1999). Stem cell emergence and hemopoietic activity are incompatible in mouse intraembryonic sites. J. Exp. Med. 190, 43-52.

Itoh, K., Tezuka, H., Sakoda, H., Konno, M., Nagata, K., Uchiyama, T., Uchino, H. and Mori, K. J. (1989). Reproducible establishment of hemopoietic supportive stromal cell lines from murine bone marrow. Exp. Hematol. 17, 145-153.

Jat, P. S., Cepko, C. L., Mulligan, R. C. and Sharp, P. A. (1986). Recombinant retroviruses encoding simian virus 40 large $\mathrm{T}$ antigen and polyomavirus large and middle T antigens. Mol. Cell Biol. 6, 12041217.

Jat, P. S., Noble, M. D., Ataliotis, P., Tanaka, Y., Yannoutsos, N., Larsen, L. and Kioussis, D. (1991). Direct derivation of conditionally immortal cell lines from an $\mathrm{H}-2 \mathrm{~K}^{\mathrm{b}}$-tsA58 transgenic mouse. Proc. Natl. Acad. Sci. USA 88, 5096-5100.

Jat, P. S. and Sharp, P. A. (1986). Large T antigens of simian virus 40 and polyomavirus efficiently establish primary fibroblasts. J. Virol. 59, 746750 .

Jordan, C. T. and Lemischka, I. R. (1990). Clonal and systemic analysis of long-term hematopoiesis in the mouse. Genes Dev. 4, 220-232. 
Klimpel, G. R., Fleischmann, W. R. and Klimpel, K. D. (1982). Gamma interferon (IFN gamma) and IFN alpha/beta suppress murine myeloid colony formation (CFU-C)N: magnitude of suppression is dependent upon level of colony-stimulating factor (CSF). J. Immunol. 129, 76-80.

Lemischka, I. R. (1991). Clonal, in vivo behavior of the totipotent hematopoietic stem cell. Semin. Immunol. 3, 349-355.

Lemoine, F. M., Dedhar, S., Lima, G. M. and Eaves, C. J. (1990). Transformation-associated alterations in interactions between pre-B cells and fibronectin. Blood 76, 2311-2320.

Lord, B. I., Testa, N. G. and Hendry, J. H. (1975). The relative spatial distributions of CFUs and CFUc in the normal mouse femur. Blood 46, 6572.

McKinstry, W. J., Li, C. L., Rasko, J. E., Nicola, N. A., Johnson, G. R. and Metcalf, D. (1997). Cytokine receptor expression on hematopoietic stem and progenitor cells. Blood 89, 65-71.

Medvinsky, A. and Dzierzak, E. (1996). Definitive hematopoiesis is autonomously initiated by the AGM region. Cell 86, 897-906.

Medvinsky, A. L., Samoylina, N. L., Muller, A. M. and Dzierzak, E. A. (1993). An early pre-liver intraembryonic source of CFU-S in the developing mouse. Nature 364, 64-67.

Metcalf, D. (ed.) (1988). The molecular control of blood cells. Cambridge, MA: Harvard University Press.

Miles, C., Sanchez, M.-J., Sinclair, A. and Dzierzak, E. (1997). Expression of the Ly-6E.1 (Sca-1) transgene in adult hematopoietic stem cells and the developing mouse embryo. Development 124, 537-547.

Montecino-Rodriguez, E., Landreth, K. S. and Dorshkind, K. (1994). Differential expression of bone marrow stromal cell-surface antigens on myeloid and lymphoid cells. Hybridoma 13, 175-181.

Moore, K. A., Ema, H. and Lemischka, I. R. (1997a). In vitro maintenance of highly purified, transplantable hematopoietic stem cells. Blood 89, 43374347.

Moore, K. A., Pytowski, B., Witte, L., Hicklin, D. and Lemischka, I. R. (1997b). Hematopoietic activity of a stromal cell transmembrane protein containing epidermal growth factor-like repeat motifs. Proc. Natl. Acad. Sci. USA 94, 4011-4016.

Moore, M. A. and Metcalf, D. (1970). Ontogeny of the haemopoietic system: yolk sac origin of in vivo and in vitro colony forming cells in the developing mouse embryo. Br. J. Haematol. 18, 279-296.

Morgan, J. E., Beauchamp, J. R., Pagel, C. N., Peckham, M., Ataliotis, P., Jat, P. S., Noble, M. D., Farmer, K. and Partridge, T. A. (1994). Myogenic cell lines derived from transgenic mice carrying a thermolabile $\mathrm{T}$ antigen: a model system for the derivation of tissue-specific and mutation-specific cell lines. Dev. Biol. 162, 486-498.

Müller, A. M., Medvinsky, A., Strouboulis, J., Grosveld, F. and Dzierzak, E. (1994). Development of hematopoietic stem cell activity in the mouse embryo. Immunity 1, 291-301.

Nakayama, N., Han, C.-H., Scully, S., Nishinakamura, R., He, C., Zeni, L., Yamane, H., Chang, D., Yu, D., Yokota, T. and Wen, D. (2001). A novel chordin-like protein inhibitor for bone morphogenetic proteins expressed preferentially in mesenchymal cell lineages. Dev. Biol. 232, 372387.

Ogawa, M. (1993). Differentiation and proliferation of hematopoietic stem cells. Blood 81, 2844-2853.

Ohneda, O., Fennie, C., Zheng, Z., Donahue, C., La, H., Villacorta, R., Cairns, B. and Lasky, L. A. (1998). Hematopoietic stem cell maintenance and differentiation are supported by embryonic aorta-gonad-mesonephros region-derived endothelium. Blood 92, 908-919.

Ohneda, O., Ohneda, K., Nomiyama, H., Zheng, Z., Gold, S. A., Arai, F., Miyamoto, T., Taillon, B. E., McIndoe, R. A., Shimkets, R. A. et al.
(2000). WECHE: a novel hematopoietic regulatory factor. Immunity 12, 141-150.

Okuyama, R., Koguma, M., Yanai, N. and Obinata, M. (1995a). Bone marrow stromal cells induce myeloid and lymphoid development of the sorted hematopoietic stem cells in vitro. Blood 86, 2590-2597.

Okuyama, R., Yanai, N. and Obinata, M. (1995b). Differentiation capacity toward mesenchymal cell lineages of bone marrow stromal cells established from temperature-sensitive SV40 T-antigen gene transgenic mouse. Exp. Cell Res. 218, 424-429.

Oostendorp, R. A. J., Harvey, K. N., Kusadasi, N., de Bruijn, M. F. T. R., Saris, C., Ploemacher, R. E., Medvinsky, A. L. and Dzierzak, E. A. (2002). Stromal cell lines from mouse aorta-gonad-mesonephros subregions are potent supporters of hematopoietic stem cell activity. Blood 99, 11831189.

Rémy-Martin, J. P., Marandin, A., Challier, B., Bernard, G., Deschaseaux, M., Herve, P., Wei, Y., Tsuji, T., Auerbach, R., Dennis, J. E. et al. (1999). Vascular smooth muscle differentiation of murine stroma: a sequential model. Exp. Hematol. 27, 1782-1795.

Ridley, A. J., Paterson, H. F., Noble, M. and Land, H. (1988). Ras-mediated cell cycle arrest is altered by nuclear oncogenes to induce Schwann cell transformation. EMBO J. 7, 1635-1645.

Sato, T., Selleri, C., Young, N. S. and Maciejewski, J. P. (1995). Hematopoietic inhibition by interferon-gamma is partially mediated through interferon regulatory factor-1. Blood 86, 3373-3380.

Selleri, C., Sato, T., Anderson, S., Young, N. S. and Maciejewski, J. P. (1995). Interferon-gamma and tumor necrosis factor-alpha suppress both early and late stages of hematopoiesis and induce programmed cell death. J. Cell Physiol. 165, 538-546.

Selleri, C., Maciejewski, J. P., Sato, T. and Young, N. S. (1996). Interferongamma constitutively expressed in the stromal microenvironment of human marrow cultures mediates potent hematopoietic inhibition. Blood 87, 41494157.

Smith, J. R. and Pereira-Smith, O. M. (1996). Replicative senescence: implications for in vivo aging and tumor suppression. Science 273, 63-67.

Tegtmeyer, P. (1975). Function of simian virus 40 gene A in transforming infection. J. Virol. 15, 613-618.

Whitehead, R. H., VanEeden, P. E., Noble, M. D., Ataliotis, P. and Jat, P. S. (1993). Establishment of conditionally immortalized epithelial cell lines from both colon and small intestine of adult $\mathrm{H}-2 \mathrm{~Kb}$-tsA58 transgenic mice. Proc. Natl. Acad. Sci. USA 90, 587-591.

Wineman, J., Moore, K., Lemischka, I. and Muller-Sieburg, C. (1996). Functional heterogeneity of the hematopoietic microenvironment: rare stromal elements maintain long-term repopulating stem cells. Blood 87, 4082-4090.

Xu, M. J., Tsuji, K., Ueda, T., Mukouyama, Y. S., Hara, T., Yang, F. C., Ebihara, Y., Matsuoka, S., Manabe, A., Kikuchi, A. et al. (1998). Stimulation of mouse and human primitive hematopoiesis by murine embryonic aorta-gonad-mesonephros-derived stromal cell lines. Blood 92, 2032-2040.

Yanai, N., Suzuki, M. and Obinata, M. (1991). Hepatocyte cell lines established from transgenic mice harboring temperature-sensitive SV 40 large T-antigen gene. Exp. Cell Res. 197, 50-56.

Yoder, M. C., Papaioannou, V. E., Breitfeld, P. P. and Williams, D. A. (1994). Murine yolk sac endoderm- and mesoderm-derived cell lines support in vitro growth and differentiation of hematopoietic cells. Blood 83, 24362443.

Yoder, M. C., King, B., Hiatt, K. and Williams, D. A. (1995). Murine embryonic yolk sac cells promote in vitro proliferation of bone marrow high proliferative potential colony-forming cells. Blood 86, 1322-1330. 